\title{
Speciation analysis of butyltin compounds in Chinese seawater by capillary gas chromatography with flame photometric detection using in-situ hydride derivatization followed by headspace solid-phase microextraction
}

\author{
Gui-bin Jiang*, Ji-yan Liu, Ke-wu Yang \\ Research Center for Eco-Environmental Sciences, Chinese Academy of Sciences, P.O. Box 2871, Beijing 100085, PR China
}

Received 18 November 1999; received in revised form 31 May 2000; accepted 14 June 2000

\begin{abstract}
A solvent-free method for the extraction of butyltin compounds from seawater by headspace solid-phase microextraction (SPME) is presented. The butyltin chlorides present in seawater was converted to its hydride forms by sodium tetrahydridoborate prior to extraction. A polydimethylsiloxane (PDMS) coated silica $100 \mu \mathrm{m}$ fiber is introduced into the headspace over seawater to extract butyltin hydrides. After extraction, the fiber is directly injected to the injector of gas chromatograph (GC) for desorption, separation and quantification. A laboratory modified flame photometric detector using quartz surface-induced tin emission (QSIL-FPD) was used throughout the experiment. The detection limits obtained with GC-QSIL-FPD for monobutyl, dibutyl, and tributyltin are 19.4, 1.5 and $0.5 \mathrm{ng} / \mathrm{l}$ as $\mathrm{Sn}$, respectively. The proposed method was applied to the speciation analysis of butyltin compounds in seawater from different part of the Chinese harbors. (C) 2000 Elsevier Science B.V. All rights reserved.
\end{abstract}

Keywords: SPME; GC-FPD; Butyltins

\section{Introduction}

Owing to its extremely toxic to aquatic life at low concentrations [1-3], tributyltin and other forms of organotin, such as phenyltin are legislatively banned to be used as antifouling paints from the late 1980s in most European and North American countries [4], however, only a few countries or regions in Asia have such regulations on the use of tributyltin as antifouling paints. In China, even no investigation was conducted to assess the occurrence and contamination of organotins in aquatic environment. Our primary goal

\footnotetext{
${ }^{*}$ Corresponding author. Fax: +86-106292-3563.

E-mail address: gbjiang@mail.rcees.ac.cn (G.-b. Jiang).
}

for the development of analytical methods is their application in environmental monitoring to achieve good assessment of the contamination situation in Chinese harbor environment.

Regarding to the analytical procedure for organotin speciation, three factors are paramount importance. First, due to butyltin compounds present in the environment are polar, involatile and associated with different counterions, such as chlorides, sulfides hydroxides and carbonates, sample preparation steps by hydride generation $[5,6]$, ethylation $[7,8]$ or Grignard alkylation [9] are needed prior to gas chromatographic separation. Secondly, organotin separation is always a challenging step. In this respect, gas chromatography is preferred for the separation due to its 
larger resolving power, possibility of identification of unknown compounds, and availability of more sensitive and on-line coupled detection techniques [10], liquid chromatography is also a method of choice because of its high capacity for the sample separation [11]. Thirdly, selective and sensitive detector is necessary for the determination of toxicological effects, especially the non-effect levels of contamination. For gas chromatography, flame photometric detector using quartz surface-induced tin emission (QSIL-FPD) or microwave-induced plasma-atomic emission are among the most sensitive and convenient techniques $[12,13]$.

In view of the sample preparation for analysis of butyltin compounds, procedure based on liquid-liquid extraction of butyltin chelates with DDTC or fresh tropolone followed by Grignard derivatization, was usually multisteps, tedious and time consuming [14]. Losses of analytes can occur and there is a potential health hazard in handing large amounts of volatile organic solvent. Another procedure based on super critical fluid extraction (SFE) with carbon dioxide needed the addition of organic modifiers of complexing agents to improve the efficiency of the extraction $[15,16]$. The solid-phase extraction (SPE) is an attractive approach when the solid-phase is housed in cartridges or disks due to the possibility of integration in on-line flow analysis $[17,18]$. For sediment or soil digestion and pretreatment, microwave-assisted derivatization solvent extraction (MADSE) provided an useful procedure [19]. Extraction techniques based on solid-phase microextraction (SPME) offer attractive alternatives to the current methods and can minimize the problems associated with those methods [20,21]. This solvent free technique is simply, fast and easy automated while eliminates the disadvantages of liquid-liquid extraction, such as operation strenuosity and analytes loss. Because entire amount of compounds adsorbed to SPME fiber can be introduced into GC, sensitivity becomes higher than that of the liquid-liquid or SPE [22]. However, to data, SPME has been mainly used for the analysis of volatile organic compounds [23-26], only a few studies can be traced from literature concerning its application to organometallic species [27-32]. Moteillo et al. [29] reported the rapid determination of methyltin in aqueous samples using SPME. Sampling was carried out directly from aqueous samples. The reproducibility (R.S.D.) of the method ranges from 5.0 to $16.3 \%$ was reported. Cai and Bayona [32] used SPME for the measurement of methylmercury in fish and river samples after derivatization with sodium tetraethylborate, relative low detection limits of 7.5 and $3.5 \mathrm{ng} / \mathrm{l}$ as $\mathrm{Hg}$ for $\mathrm{CH}_{3} \mathrm{Hg}^{+}$ and $\mathrm{Hg}^{2+}$ were obtained.

In this study, several commercial available fibers was tested for the extraction of butyltin species from seawater. Factors that affected the performance of SPME have been studied and optimized. The proposed method has low ng/l levels of detection limits and is characterized by simple and good reproducibility.

\section{Experimental}

\subsection{Apparatus}

A Shimadzu (Kyoto, Japan) GC-9A gas chromatograph equipped with a laboratory made flame photometric detector using QSIL-FPD was used [33]. The analytical column was $25 \mathrm{~m} \times 0.32 \mathrm{~mm}$ (i.d.) $\mathrm{HP}-1$ fused silica capillary column coated with $0.17 \mu \mathrm{m}$ film thickness of methylsilicone (Hewlett Packard, USA). The oven temperature was initially held at $55^{\circ} \mathrm{C}$ for $1 \mathrm{~min}$, programmed at $10^{\circ} \mathrm{C} / \mathrm{min}$ to the final temperature of $150^{\circ} \mathrm{C}$, and then held for $3 \mathrm{~min}$. The injector and detector temperature were set at 220 and $140^{\circ} \mathrm{C}$, respectively. High purity nitrogen was used as the carrier gas and column head pressure was kept at $260 \mathrm{kPa}$. Hydrogen and air were maintained at flow rates of 260 and $90 \mathrm{ml} / \mathrm{min}$, respectively.

The manual SPME device used was obtained from Supelco (Supelco, Bellefonte, PA, USA). The following fibers coated with stationary phase of different natures and various film thickness were investigated: polydimethylsiloxane (PDMS) with 100, 30 and $7 \mu \mathrm{m}$ coating, polyacrylate (PA) with $80 \mu \mathrm{m}$ coating, and PDMS-divinylbenzene (PDMS-DVB) with $65 \mu \mathrm{m}$ coating.

\subsection{Reagents}

Monobutyltin trichloride (MBT, 97\%), dibutyltin dichloride (DBT, 97\%), tributyltin chloride (TBT, 90\%) and tetrabutyltin (TeBT, 96\%) were obtained from Acros Organics (NJ, USA). Stock solutions of butyltin compounds were separately prepared at concentration levels of $1 \mathrm{mg} / \mathrm{ml}$ as tin in methanol. 
Working solutions were gradually diluted by deionized water before measurement. All the solutions were stored at $4^{\circ} \mathrm{C}$ in the dark.

Sodium tetrahydridoborate $\left(\mathrm{NaBH}_{4}, 99.7 \%\right)$ was obtained from Acros Organics (NJ, USA). A fresh solution of $3 \%(\mathrm{w} / \mathrm{v})$ was prepared daily with deionized water.

Buffer solution with $\mathrm{pH}$ value of 3.3 was the mixture of acetic acid and sodium acetate solutions. Small amount of $\mathrm{HCl}$ and $\mathrm{NaOH}$ were needed to adjust $\mathrm{pH}$ of seawater samples. All solvents and reagents used were of analytical reagent grade or better.

Glassware was rinsed with deionized water, decontaminated overnight in 1:1 nitric acid solution and then rinsed thrice with deionized water.

\subsection{Analytical procedure}

In a $150 \mathrm{ml}$ glass vial, $50 \mathrm{ml}$ of $0.1 \mathrm{~mol} / \mathrm{l}$ acetic acid and sodium acetate buffer solution was poured. Working solution of MBT, DBT and TBT were added. The vial was sealed with a septum cap and then $1 \mathrm{ml} 3 \%$ sodium tetrahydridoborate solution was injected. The solution was stirred with magnetic stirrer. The needle of the SPME device was passed through the septum. The fiber was then pushed out from the needle and exposed to the headspace of the vial for $15 \mathrm{~min}$ to extract the butyltin hydrides. Inside the vial butyltin compounds react with $\mathrm{NaBH}_{4}$ under acidic conditions to yield corresponding more volatile hydride derivatives. The extraction is an equilibrium process between the liquid phase and the headspace, when the equilibrium is reached, the fiber was withdrawn into the needle. Immediately after pulled out from the vial, the needle was directly inserted to the GC injector port for thermal desorption. The fiber was left inside the injector of GC for $10 \mathrm{~min}$ for complete desorption. Then organotin hydrides were separated in capillary column and detected by flame photometric detector.

\section{Result and discussion}

\subsection{Effect of the fiber coating thickness and natures}

For organic compounds, based on the principle of 'like dissolves like', nonpolar compounds are more likely to be extracted by nonpolar coatings, or vice

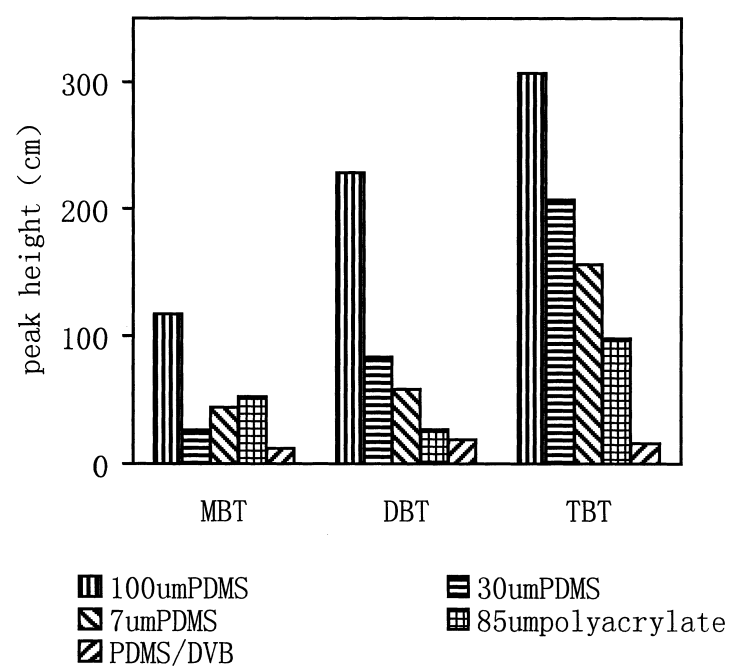

Fig. 1. Sensitivity comparison of fiber coated with various nature and thickness coating: $1000 \mathrm{ng}$ MBT, $100 \mathrm{ng}$ DBT, $100 \mathrm{ng}$ TBT and $80 \mathrm{ng}$ TeBT standard were spiked to $50 \mathrm{ml}$ water $-(\times)$ MBT, $(\bigcirc)$ DBT, $(\square)$ TBT, $(\diamond)$ TeBT.

versa. Generally, organotin hydrides extracted by SPME fiber are also less polar compounds, with the number of butyl substitutes increasing, the polarity of butyltin hydrides decreases correspondingly, and the affinity of nonpolar coating for butyltin hydrides increases. So it can be seen from Fig. 1, sensitivity of nonpolar PDMS coatings are the best in all of the fibers tested. Among three butyltin species, tributyltin hydride appeared high sensitive than dibutyltin dihydride and monobutyltin trihydride when extracted by nonpolar PDMS coating.

As for different coating thickness, Fig. 1 showed that the butyltins extracted by $100 \mu \mathrm{m}$ PDMS is more effective than its 30 and $7 \mu \mathrm{m}$ coatings. This is because the amount of analyte extracted by the fiber coating is directly proportioned to the volume of the coating [31]. Thus, increasing the volume and thickness of the coating, or the length of the fiber, are among the most effective way to improve extraction efficiency.

\subsection{Effect of exposure time}

If thickness and characteristics of the fiber coating is varied, the optimum exposure time will be different. Fig. 2a-c showed that the optimum extraction time for $100,30,7 \mu \mathrm{m}$ PDMS coatings are varied from 5 to 

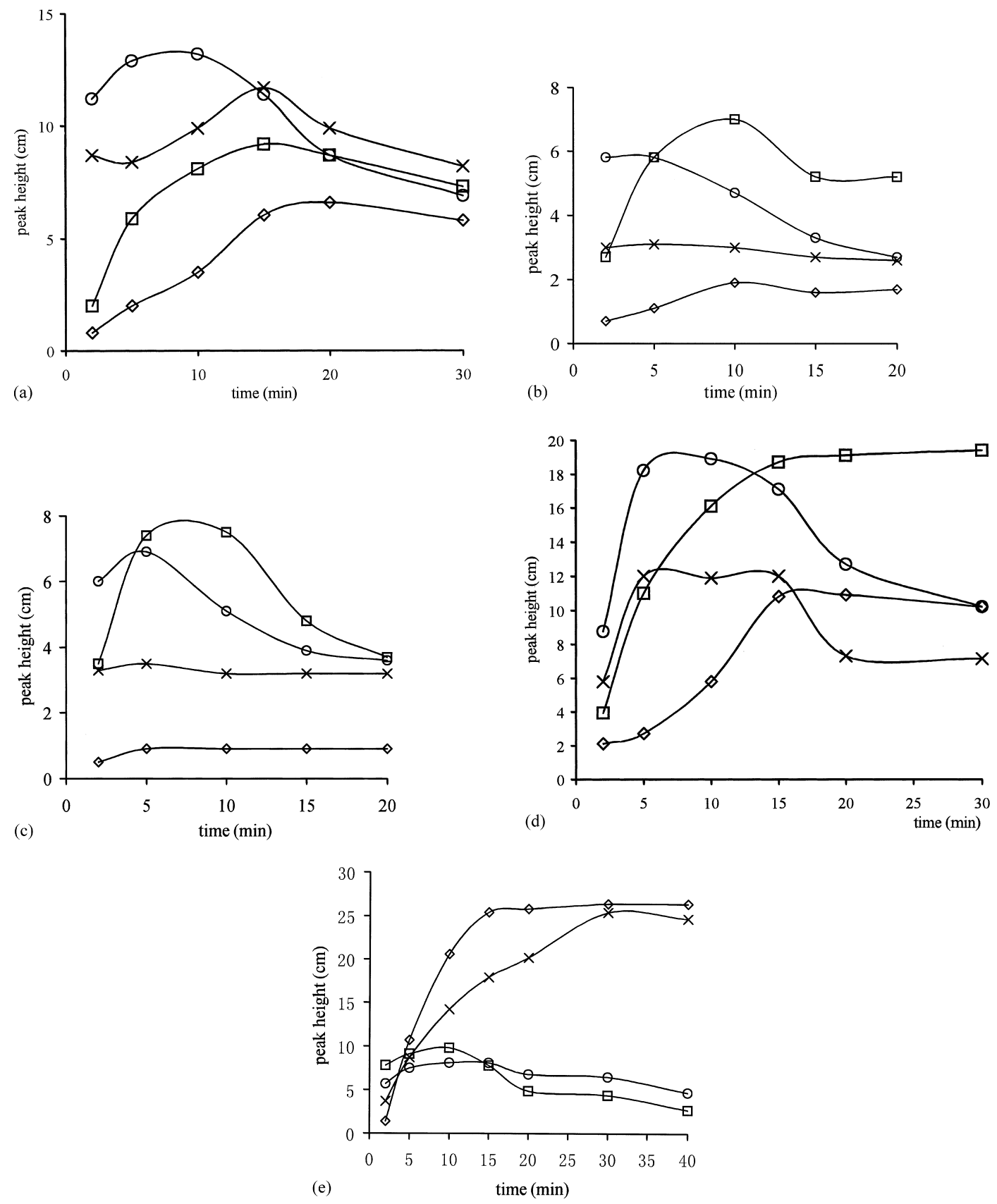

Fig. 2. Extraction time of fiber coated with various nature and thickness static phase. (a) $100 \mu \mathrm{m}$ PDMS coating: $100 \mathrm{ng}$ MBT, $5 \mathrm{ng}$ DBT, $3 \mathrm{ng}$ TBT and $4 \mathrm{ng}$ TeBT standard were spiked to $50 \mathrm{ml}$ water $-(\times)$ MBT, (○) DBT, ( $\square$ ) TBT, $(\diamond)$ TeBT; (b) $30 \mu \mathrm{m}$ PDMS coating: $100 \mathrm{ng}$ MBT, $5 \mathrm{ng}$ DBT, $3 \mathrm{ng}$ TBT and $4 \mathrm{ng}$ TeBT standard were spiked to $50 \mathrm{ml}$ water $-(\times)$ MBT, $(\bigcirc)$ DBT, $(\square) \mathrm{TBT},(\diamond) \mathrm{TeBT} ;(\mathrm{c})$ $7 \mu \mathrm{m}$ PDMS coating: $200 \mathrm{ng}$ MBT, $15 \mathrm{ng}$ DBT, $6 \mathrm{ng}$ TBT and $0.24 \mathrm{ng}$ TeBT standard were spiked to $50 \mathrm{ml}$ water $-(\times)$ MBT, $(\bigcirc)$ DBT, $(\square)$ TBT, $(\diamond)$ TeBT; (d) $65 \mu \mathrm{m}$ PDMS/DVB coating: $1000 \mathrm{ng}$ MBT, $100 \mathrm{ng}$ DBT, $100 \mathrm{ng}$ TBT and $80 \mathrm{ng}$ TeBT standard were spiked to $50 \mathrm{ml}$ water $-(\times)$ MBT, $(\bigcirc)$ DBT, $(\square)$ TBT, $(\diamond)$ TeBT; (e) $85 \mu \mathrm{m}$ PA coating: $1000 \mathrm{ng}$ MBT, $30 \mathrm{ng}$ DBT, $10 \mathrm{ng}$ TBT and $40 \mathrm{ng}$ TeBT standard were spiked to $50 \mathrm{ml}$ water $-(\times)$ MBT, $(\bigcirc)$ DBT, $(\square)$ TBT, $(\diamond)$ TeBT. 
$15 \mathrm{~min}$. It is obvious that the thicker the coating is, the longer the equilibrium time is needed. It is possibly related to the mass transport of the analytes in the coating. Similarly, PDMS-DVB with $65 \mu \mathrm{m}$ coating in Fig. $2 \mathrm{~d}$ takes $15 \mathrm{~min}$ but PA with $80 \mu \mathrm{m}$ coating in Fig. 2e needs more time to collect the analytes. Therefore, when we choosing thickness of the fiber, extraction time should be take consideration.

\subsection{Effect of temperature}

The extraction process involves two equilibrium steps in headspace SPME mode, hence there are two coefficients, namely $K_{1}$, the partition coefficient between the fiber coating and the headspace gas phase, and $K_{2}$, the partition coefficient between gas phase and liquid phase. Therefore, the total constant of the process $K=K_{1} K_{2}$ depends both on the volatility of the compounds and the fiber affinity character [31]. Heating the samples increases $K_{2}$ and, thus, helps to release analytes from matrix to the headspace. To some extent, heating is a convenient method to improve extraction efficiency. But lower temperature facilitates the physical adsorption process on fibers. If temperature increases, $K_{1}$ drops, the ability of fibers adsorbing analytes will decrease [21].

We studied the temperature effect between 2 and $60^{\circ} \mathrm{C}$. Fig. 3 shows the results obtained by using

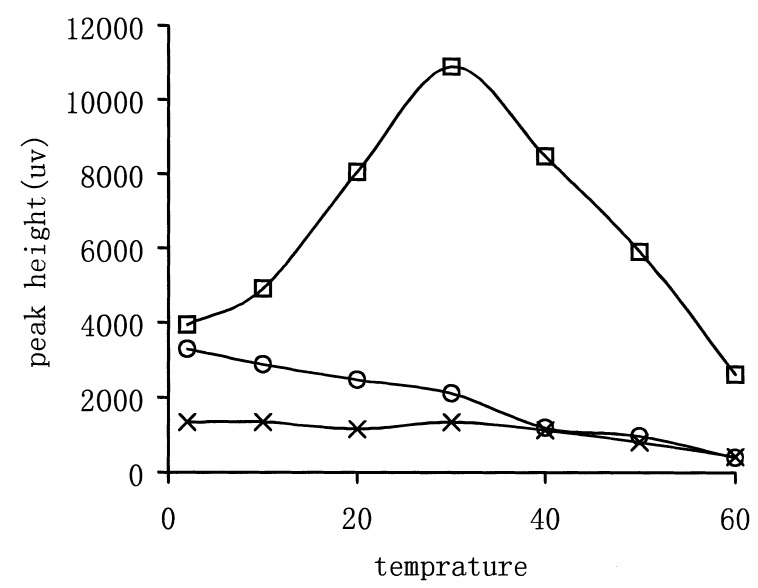

Fig. 3. Effect of temperature: $1000 \mathrm{ng}$ MBT, $100 \mathrm{ng}$ DBT, $100 \mathrm{ng}$ TBT and $80 \mathrm{ng}$ TeBT standard were spiked to $50 \mathrm{ml}$ water $-(\times)$ MBT, (O) DBT, ( $\square)$ TBT.
$100 \mu \mathrm{m}$ PDMS coated fiber. As shown in Fig. 3, with the temperature increasing, the amount of MBT and DBT extracted by the fiber decrease slowly, this is mainly due to the MBT and DBT desorbed from the fiber. However, tributyltin, with the highest boiling point among all of three butyltins, has a sharp rise at $30^{\circ} \mathrm{C}$ on the trend curve. It is indicated that by increasing temperature, the increased $K_{2}$ value is much bigger than the decreased $K_{1}$ value.

As the operating temperature is high than $60^{\circ} \mathrm{C}$, the aqueous steam can evaporate and become small drops on the fiber surface, results in a disadvantage of poor peaks broadening and tailing when such fiber was directly introduced into GC column. For routine operation, all the experiments were performed around $30^{\circ} \mathrm{C}$.

\subsection{Reproducibility, precision and recovery}

To assess the reproducibility of the proposed method, $200 \mathrm{ng}$ MBT, $10 \mathrm{ng}$ DBT and $10 \mathrm{ng}$ TBT were spiked to $50 \mathrm{ml}$ seawater and measured by 100,30 and $7 \mu \mathrm{m}$ PDMS, $65 \mu \mathrm{m}$ PDMS-DVB and $85 \mu \mathrm{m}$ PA, respectively. Table 1 summarizes the relative standard deviations of three butyltin compounds using fiber coatings of different polarity and thickness. The data are averages of seven times repeat measurements; the relative standard deviations (R.S.D.) of all data points using $100 \mu \mathrm{m}$ PDMS fiber coating was below $8.4 \%$, indicating a sufficient reproducibility. The precision of the proposed method in optimized experimental conditions was evaluated by measuring seawater sample. Nine times repeated determination showed the R.S.D. values were $9.0 \%$ for MBT, $6.8 \%$ for DBT and $11.1 \%$ for TBT, respectively. The recovery data are $93 \pm 8$ for MBT, $104 \pm 10$ for DBT and $103 \pm 7$ for TBT, respectively.

Table 1

Reproducibility of different fiber coatings and thickness

\begin{tabular}{llllll}
\hline Species & \multicolumn{5}{l}{ Fiber coating } \\
\cline { 2 - 6 } & $100 \mu \mathrm{m}$ & $30 \mu \mathrm{m}$ & $7 \mu \mathrm{m}$ & $65 \mu \mathrm{m}$ & $85 \mu \mathrm{m}$ \\
& PDMS & PDMS & PDMS & PDMS-DVB & PA \\
\hline MBT & 4.0 & 13.7 & 10.3 & 18.5 & 4.1 \\
DBT & 8.3 & 8.3 & 7.1 & 15.3 & 6.6 \\
TBT & 8.4 & 8.1 & 14.1 & 21.7 & 12.6 \\
\hline
\end{tabular}


Table 2

Calibration data for butyltin species

\begin{tabular}{lllclc}
\hline Species & Concentration range $(\mu \mathrm{g} / \mathrm{l})$ & Slope $(m)$ & $Y$-intercept & Correlation coefficient $(\gamma)$ & Detection limit $(\mathrm{ng} / \mathrm{l})$ \\
\hline MBT & $0-2.0$ & 61.1 & -60.9 & 0.9982 & 19.4 \\
DBT & $0-0.1$ & 1450 & 8.6 & 0.9992 & 1.5 \\
TBT & $0-0.1$ & 2759 & 51 & 0.9915 & 0.5 \\
\hline
\end{tabular}

\subsection{Calibration and detection limits}

The quantitative determination of seawater samples was accomplished by using the calibration curves, which was obtained by plotting the GC-QSIL-FPD responses (peak height counts) versus the analyte concentration. Table 2 listed the calibration ranges, slopes and the correlation coefficients and the detection limits (LODs). The detection limits of MBT, DBT, and TBT are $19.4 \mathrm{ng} / \mathrm{l}$ for MBT, $1.5 \mathrm{ng} / \mathrm{l}$ for DBT and $0.5 \mathrm{ng} / \mathrm{l}$ for TBT as Sn, respectively, which indicated that this method using SPME technique offers high sensitivity for butyltin hydrides.

\subsection{Comparison of SPME and liquid-liquid extraction for organotin analysis}

As indicated in many literature, the traditional procedure of the sample preparation based on liquid-liquid extraction of the derivatized organotins was usually multisteps, tedious and time consuming. Losses of analytes and use of large amounts of toxic organic solvent seriously obstructed the feasibility of these methods. Compares with L-L extraction, SPME is solvent free, simple, fast, easy automated and requires no complicated apparatus. With this technique, extraction and concentration can be realized in just one step. Since SPME has been mainly used for the analysis of volatile organic compounds, for polar and relative involatile butyltin compounds, a procedure by adding sodium tetrahydridoborate $\left(\mathrm{NaBH}_{4}\right)$ to form hydride derivatives prior to extraction is important.

\subsection{Sample analysis}

Seawater samples obtained from Chinese coastal areas were acidified to $\mathrm{pH} 2$ and stored at $4{ }^{\circ} \mathrm{C}$ until analysis. Table 3 shows the concentration data obtained from different site. Sources of butyltin compounds into marine environment is mainly due to the antifouling paints other than industrial and agricultural usage.

The most important compound to consider is TBT due to the toxicity of butyltin compounds declines substantially with the decreasing number of butyl groups. During our investigation, tributyltin was detected in 14 of 19 samples. Most of these samples were found in areas of heavy boating, shipping traffic or shipyard, which is consistent with its use in some antifouling paints for boats, ships and docks. The highest concentration of tributyltin found was in Qingdao Beihai dock yard (976.9 ng Sn/1). This concentration is about half of the $12 \mathrm{~d}$ LC-100 value of $1.83 \mu \mathrm{g} \mathrm{Sn} / 1$ for adult rainbow trout yolk sac fry [34]. At another location of Fuxing East Road, Shanghai Huangpu river, the tributyltin concentration (425.3 ng Sn/l) was >400 ng Sn/l, a concentration which was the $48 \mathrm{~h} \mathrm{EC}_{50}$ (response to prodding) for the most sensitive fresh water organism, a coelenterate (Hydra sp.) in acute toxicity tests [35]. At further two locations the tributyltin concentration exceeds $70 \mathrm{ng} \mathrm{Sn} / \mathrm{l}$, a concentration at which growth retardation of rainbow trout yolk sac fry over $110 \mathrm{~d}$ was observed, but was significant only during the last few weeks of exposure period [34]. Therefore, in four of these 19 locations at which tributyltin was determined reliably, there may be cause for concern with regard to chronic toxicity or effects in sensitive organisms. These four samples represent $21.1 \%$ of all locations at which water samples were taken.

The ratio of the TBT concentration to the total butyltin concentration of a water sample has been used as an approximate measure of the extent to which TBT has undergone degradation at any particular location [36]. A high TBT/total butyltin concentration ratio indicates little degradation of TBT and/or recent input of TBT to water system. We found TBT percentages in Qingdao Beihai dock yard and Shanghai Fuxing East Road ship port were high to 98 and $88 \%$, which may indicate fairly recent contamination by continuing leaching of TBT from the hulls of large vessels. 
Table 3

Concentration of butyltins in seawater samples

\begin{tabular}{|c|c|c|c|c|}
\hline \multirow[t]{2}{*}{ Sample source } & \multirow[t]{2}{*}{ Sample volume (ml) } & \multicolumn{3}{|c|}{ Mean $^{\mathrm{a}}$ level \pm S.D. ${ }^{\mathrm{b}}$ (ng/l) } \\
\hline & & MBT & DBT & TBT \\
\hline Dalian harbor & 50 & $40.5 \pm 2.7$ & $19.7 \pm 2.0$ & $18.8 \pm 0.7$ \\
\hline Dalian new dock yard & 5 & $883.8 \pm 56.5$ & $185.5 \pm 11.6$ & $203.7 \pm 23.0$ \\
\hline Qinhuangdao coal wharf & 50 & $77.9 \pm 5.0$ & $15.4 \pm 0.7$ & n.d. ${ }^{\mathrm{c}}$ \\
\hline Shanhaiguan dock yard & 50 & $50.1 \pm 4.2$ & $50.1 \pm 3.7$ & $22.2 \pm 1.9$ \\
\hline Qinhuangdao wharf & 50 & $45.6 \pm 3.9$ & $33.9 \pm 0.8$ & $5.6 \pm 0.6$ \\
\hline Qinhuangdao passenger wharf & 50 & n.d. & $32.8 \pm 0.7$ & n.d. \\
\hline Tianjin Huanhai dock yard & 50 & $34.1 \pm 4.4$ & $10.2 \pm 0.8$ & $17.2 \pm 1.1$ \\
\hline Tianjin first dock board & 50 & n.d. & $60.3 \pm 3.0$ & $31.8 \pm 1.8$ \\
\hline Tianjin dock yard & 5 & $243.3 \pm 34.0$ & $48.6 \pm 3.9$ & $322.4 \pm 14.1$ \\
\hline Qingdao Beihai dock yard & 10 & n.d. & $24.0 \pm 0.9$ & $976.9 \pm 30.0$ \\
\hline Qingdao harbor & 25 & n.d. & $5.0 \pm 0.7$ & $49.4 \pm 3.4$ \\
\hline Huangdao breed section & 50 & n.d. & n.d. & n.d. \\
\hline Lianyungang harbor & 50 & $106.0 \pm 3.9$ & n.d. & n.d. \\
\hline Jiangyin ferry (Yangzi River) & 50 & $132.3 \pm 3.1$ & n.d. & $10 \pm 1$ \\
\hline Huangpu tourist ship port & 50 & n.d. & $8.1 \pm 0.6$ & $10.6 \pm 0.4$ \\
\hline Shanghai Fuxing Road ship port & 50 & $49.5 \pm 1.5$ & $8.5 \pm 0.4$ & $425.3 \pm 9.0$ \\
\hline West Lake & 50 & $39.3 \pm 3.0$ & $7.2 \pm 0.2$ & $3.7 \pm 0.1$ \\
\hline Yantai bathing beach & 50 & $397.9 \pm 29.8$ & $3.6 \pm 0.2$ & n.d. \\
\hline Guangxi Beihai & 50 & $125.2 \pm 16.4$ & n.d. & $14.8 \pm 1.5$ \\
\hline
\end{tabular}

The TBT percentages for Tianjin dock yard of 52.4 and $56.7 \%$ for Shanghai Huangpu tourist ship port presumably reflect more degradation. In other place, the low percentage of TBT may indicate there are other sources of DBT and MBT besides the debutylation of TBT to great extent.

\section{Conclusions}

Headspace SPME using $100 \mu \mathrm{m}$ PDMS-coated fiber combined with capillary gas chromatography and a laboratory-made flame photometric detector using QSIL-FPD offers an alternative method of choice for the extraction and quantitative analysis of ultratrace levels of butyltin compounds in seawater. The overall sample processing is simple with substantially shorter extraction time, and moreover, harmful organic extractant is avoided. Experimental results showed the wide distribution of butyltin compounds in Chinese aquatic system. In some locations, the concentrations of this drastic toxic compound are rather high than the toxicity threshold of the aquatic organisms, which may affect the natural ecosystem and the human body. We are now making an effort to analysis a large number of samples from various Chinese locations in order to further evaluate the occurrence and pollution situation in China.

\section{Acknowledgements}

This work was jointly supported by the Chinese Academy of Sciences under Contract No. KZ951-B1-209, RCEES9902 and the National Natural Science Foundation of China under Contract No. 29825114.

\section{References}

[1] J.A.J. Thompson, M.G. Sheffer, R.C. Pierce, Y.K. Chau, J.J. Cooney, W.R. Cullen, R.J. Maguire, NRCC/CNRC 22494, Ottawa, Canada, 1985.

[2] J.E. Thain, M.J. Waldock, Water Sci. Technol. 18 (1986) 193-202.

[3] A.O. Valkirs, B.M. Davidson, P.F. Seligman, Chemosphere 16 (1987) 201-220. 
[4] Y.K. Chau, R.J. Maguire, M. Brown, F. Yang, S.P. Batchelor, Water Qual. Res. J. Canada 32 (1997) 453-521.

[5] O.F.X. Donard, S. Rapsomanikis, J.H. Weber, Anal. Chem. 58 (1986) 772-776.

[6] M.O. Andreae, J.T. Byrd, Anal. Chim. Acta 156 (1984) 147157.

[7] J. Ashby, S. Clark, P.J. Craig, J. Anal. At. Spectrom. 3 (1988) 735-736.

[8] P. Michel, B. Averty, Appl. Organomet. Chem. 5 (1991) 393397.

[9] M.D. Muller, Anal. Chem. 59 (1987) 617-623.

[10] R. Lobinski, Analusis 22 (1994) 37-48.

[11] W. Langseth, J. Chromatogr. A 315 (1984) 351-357.

[12] G.B. Jiang, P.S. Maxwell, K.W.M. Siu, V.T. Luong, S.S. Berman, Anal. Chem. 63 (1991) 1506-1509.

[13] W. Dirkx, R. Lobinski, F.C. Adams, Anal. Sci. 9 (1993) 273278.

[14] M. Abalos, J.M. Bayona, R. Compano, M. Granados, C. Leal, M.D. Prat, J. Chromatogr. A 788 (1997) 1-49.

[15] R. Alzaga, J.M. Bayona, J. Chromatogr. A 655 (1993) 51-56.

[16] J. Dachs, R. Alzaga, J.M. Bayona, Ph. Quevauviller, Anal. Chim. Acta 286 (1994) 319-327.

[17] O. Evans, B.J. Jacobs, A.L. Cohen, Analyst 116 (1991) 1519.

[18] S. Chiavarini, C. Cremisini, T. Ferri, R. Morabito, C. Ubaldi, Appl. Organomet. Chem. 6 (1992) 147-153.

[19] O.F.X. Donard, B. Lalere, F. Martin, R. Lobinski, Anal. Chem. 67 (1995) 4250-4254.

[20] C.L. Arthur, J. Pawliszyn, Anal. Chem. 62 (1990) 2145-2148.

[21] Z. Zhang, M.J. Yang, J Pawliszyn, Anal. Chem. 66 (1994) 844A-853A.
[22] X.P. Lee, T. Kumazawa, K. Sato, O. Suzuki, J. Chromatogr. Sci. 35 (1997) 302-308.

[23] D.W. Potter, J. Pawliszyn, J. Chromatogr. 625 (1992) 247 255.

[24] X.P. Lee, T. Kumazawa, K. Sato, O. Suzuki, Chromatographia 42 (1996) 135-140.

[25] Y. Liu, M.L. Lee, K.J. Hageman, Y. Yang, S.B. Hawthorne, Anal. Chem. 69 (1997) 5001-5005.

[26] S. Magdic, A. Boyd-Boland, K. Jinno, J. Pawliszyn, J. Chromatogr. A 736 (1996) 219-228.

[27] J. Poerschmann, F.D. Kopinke, J. Pawliszyn, Environ. Sci. Technol. 31 (1997) 3629-3636.

[28] G. Lespes, V. Desauziers, C. Montigny, M. Potin-Gautier, J. Chromatogr. A 826 (1998) 67-76.

[29] Y. Moteillo, Y. Cai, J.M. Bayona, J. High Resol. Chromatogr. 18 (1995) 767-770.

[30] T. Gorecki, J. Pawliszyn, Anal. Chem. 68 (1996) 3008-3014.

[31] Z. Zhang, J. pawliszyn, Anal. Chem. 65 (1993) 1843-1852.

[32] Y. Cai, J.M. Bayona, J. Chromatogr. A 696 (1995) 113-122.

[33] G.B. Jiang, M. Ceulemans, F.C. Adams, J. Chromatogr. 727 (1996) 119-129.

[34] W. Seinen, T. Helder, H. Vernij, A. Penninks, P. Leeuwangh, Sci. Total Environ. 19 (1981) 155-166.

[35] L.T. Brooke, D.J. Call, S.H. Poirier, T.P. Markee, C.A. Lindberg, D.J. McCauley, P.G. Simonson, Acute toxicity and chronic effects of bis(tri- $n$-butyltin) oxide to several species of freshwater organisms, Center for Lake Superior Environmental Studies Report, University of Wisconsin-Superior, Superior, WI, 1986.

[36] D.S. Page, C.C. Ozbal, M.E. Lanphear, Environ. Pollut. 91 (1996) 237-243. 